Bull. Austral. Math. Soc.

VoL. 66 (2002) [171-171]

\title{
Subnormal structure of finite soluble groups
}

\section{C.J.T. WeTHERELL}

The Wielandt subgroup, the intersection of normalizers of subnormal subgroups, is non-trivial in any finite group and thus gives rise to a series whose length is a measure of the complexity of a group's subnormal structure. Another measure, akin to the nilpotency class of nilpotent groups, arises from the strong Wielandt subgroup, the intersection of centralizers of nilpotent subnormal sections. This thesis begins an investigation into how these two invariants relate in finite soluble groups.

Complete results are obtained for metabelian groups of odd order: the strong Wielandt length of such a group is at most one more than its Wielandt length, and this bound is best possible. Some progress is made in the wider class of groups with $p$-length 1 for all primes $p$. A conjecture for all finite soluble groups, which may be regarded as a subnormal analogue of the embedding of the Kern, is also considered.

This thesis is available in PDF format from the Australian Digital Theses Program, http://thesis.anu.edu.au/ .

Institute of Mathematical Sciences

Australian National University

Canberra ACT 0200

Australia

chrisw@maths.anu.edu.au

Received 4th March, 2002

Thesis submitted to The Australian National University, September 2001. Degree approved, January 2002. Supervisor: Dr. John Cossey.

Copyright Clearance Centre, Inc. Serial-fee code: 0004-9727/02 \$A2.00+0.00. 